NASA/TM-2005-213575

\title{
Geometry and Reynolds-Number Scaling on an Iced Business-Jet Wing
}

Sam Lee

QSS Group, Inc., Cleveland, Ohio

Thomas P. Ratvasky

Glenn Research Center, Cleveland, Ohio

Michael Thacker

Cessna Aircraft Company, Wichita, Kansas

Billy P. Barnhart

Bihrle Applied Research, Inc., Jericho, New York 
Since its founding, NASA has been dedicated to the advancement of aeronautics and space science. The NASA Scientific and Technical Information (STI) Program Office plays a key part in helping NASA maintain this important role.

The NASA STI Program Office is operated by Langley Research Center, the Lead Center for NASA's scientific and technical information. The NASA STI Program Office provides access to the NASA STI Database, the largest collection of aeronautical and space science STI in the world. The Program Office is also NASA's institutional mechanism for disseminating the results of its research and development activities. These results are published by NASA in the NASA STI Report Series, which includes the following report types:

- $\quad$ TECHNICAL PUBLICATION. Reports of completed research or a major significant phase of research that present the results of NASA programs and include extensive data or theoretical analysis. Includes compilations of significant scientific and technical data and information deemed to be of continuing reference value. NASA's counterpart of peerreviewed formal professional papers but has less stringent limitations on manuscript length and extent of graphic presentations.

- TECHNICAL MEMORANDUM. Scientific and technical findings that are preliminary or of specialized interest, e.g., quick release reports, working papers, and bibliographies that contain minimal annotation. Does not contain extensive analysis.

- CONTRACTOR REPORT. Scientific and technical findings by NASA-sponsored contractors and grantees.
- CONFERENCE PUBLICATION. Collected papers from scientific and technical conferences, symposia, seminars, or other meetings sponsored or cosponsored by NASA.

- SPECIAL PUBLICATION. Scientific, technical, or historical information from NASA programs, projects, and missions, often concerned with subjects having substantial public interest.

- TECHNICAL TRANSLATION. Englishlanguage translations of foreign scientific and technical material pertinent to NASA's mission.

Specialized services that complement the STI Program Office's diverse offerings include creating custom thesauri, building customized databases, organizing and publishing research results ... even providing videos.

For more information about the NASA STI Program Office, see the following:

- Access the NASA STI Program Home Page at http://www.sti.nasa.gov

- E-mail your question via the Internet to help@sti.nasa.gov

- Fax your question to the NASA Access Help Desk at 301-621-0134

- Telephone the NASA Access Help Desk at 301-621-0390

- Write to:

NASA Access Help Desk

NASA Center for AeroSpace Information 7121 Standard Drive

Hanover, MD 21076 
NASA/TM-2005-213575

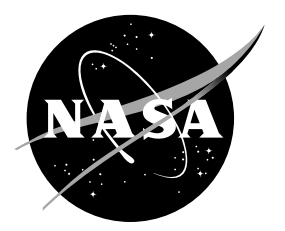

\section{Geometry and Reynolds-Number Scaling on an Iced Business-Jet Wing}

Sam Lee

QSS Group, Inc., Cleveland, Ohio

Thomas P. Ratvasky

Glenn Research Center, Cleveland, Ohio

Michael Thacker

Cessna Aircraft Company, Wichita, Kansas

Billy P. Barnhart

Bihrle Applied Research, Inc., Jericho, New York

Prepared for the

43rd Aerospace Sciences Meeting and Exhibit

sponsored by the American Institute of Aeronautics and Astronautics

Reno, Nevada, January 10-13, 2005

National Aeronautics and

Space Administration

Glenn Research Center 


\section{Acknowledgments}

The authors would like to thank the ODU and Bihrle Applied Research personnel at the Langley Full-Scale Wind Tunnel for their long hours in support of this test. Special thanks also go to the staff at the University of Illinois Subsonic Wind Tunnel.

Available from

NASA Center for Aerospace Information 7121 Standard Drive

Hanover, MD 21076
National Technical Information Service 5285 Port Royal Road Springfield, VA 22100 


\title{
Geometry and Reynolds-Number Scaling on an Iced Business-Jet Wing
}

\author{
Sam Lee \\ QSS Group, Inc. \\ Cleveland, Ohio 44135 \\ Thomas P. Ratvasky \\ National Aeronautics and Space Administration \\ Glenn Research Center \\ Cleveland, Ohio 44135 \\ Michael Thacker \\ Cessna Aircraft Company \\ Wichita, Kansas 67218 \\ Billy P. Barnhart \\ Bihrle Applied Research, Inc. \\ Jericho, NewYork 11753
}

A study was conducted to develop a method to scale the effect of ice accretion on a full-scale business jet wing model to a 1/12-scale model at greatly reduced Reynolds number. Full-scale, 5/12-scale, and 1/12-scale models of identical airfoil section were used in this study. Three types of ice accretion were studied: 22.5-minute ice protection system failure shape, 2-minute initial ice roughness, and a runback shape that forms downstream of a thermal anti-ice system. The results showed that the 22.5-minute failure shape could be scaled from full-scale to 1/12-scale through simple geometric scaling. The 2-minute roughness shape could be scaled by choosing an appropriate grit size. The runback ice shape exhibited greater Reynolds number effects and could not be scaled by simple geometric scaling of the ice shape.

\section{Nomenclature}

$\begin{array}{ll}C_{L} & \text { Lift coefficient } \\ C_{L, m a x} & \text { Maximum lift coefficient } \\ C_{m} & \text { Pitching moment coefficient } \\ L W C & \text { Liquid water content } \\ M V D & \text { Median volumetric diameter } \\ O A T & \text { Outside air temperature } \\ q & \text { Freestream dynamic pressure } \\ R e & \text { Reynolds number } \\ V & \text { Airspeed } \\ \alpha & \text { Angle of attack } \\ \mathrm{D} & \text { Measurement uncertainty }\end{array}$

\section{Introduction}

An effort is currently underway by NASA, Cessna, and Bihrle Applied Research to develop icing-effects flight simulation models for a typical business jet aircraft. These flight simulation models will be utilized in two ways: 1) The icing flight simulation will be examined as a potential new tool for systems safety to refine hazard classification for ice protection system failure cases, and 2) the icing flight simulation will be implemented into a flight training device for pilot training. A previous effort resulted in the development of an icing flight simulation demonstrator for a turbo-prop commuter class aircraft., ${ }^{1,2,3}$

The flight model used in the flight simulator will come from testing a 1/12-scale complete aircraft model in a rotary-balance wind tunnel. Because of the significant reduction in both the geometry and the Reynolds number, the scaling relationship between the full-scale aircraft and the subscale model needed to be known. 
Previous experimental and computational results with subscale airfoils ${ }^{3,4,5}$ have shown that iced-airfoil aerodynamics is relatively insensitive to Reynolds number effects. Because of this, simple geometric scaling of the ice shapes has provided very good results for subscale geometry and Reynolds number tests. However, there are several factors unique to this effort that may not allow the practice of simply geometrically scaling the ice shapes.

Wind tunnel size constraints dictated a 1/12-scale model for the complete airplane test. The rotation rate and oscillation frequency capabilities of the dynamic test rig determined the wind tunnel velocity that would provide the desired range of non-dimensionalized rates. These geometric and wind velocity constraints resulted in a Reynolds number of approximately 5 percent of that of the full-scale airplane. There is little study in the literature in which the airfoil geometry and Reynolds number have been scaled to this degree. It was expected that the subscale cleanaircraft lift coefficient could be lower than that of the full-scale iced aircraft. Another factor was the desire to test a runback ice shape that forms well downstream of the leading edge. Reynolds number insensitivity of leading edge ice shapes has been established through numerous studies. However, the effect of Reynolds number on ice shapes that form far downstream of the leading edge is not as well understood. Finally, a two-minute ice shape (primarily surface roughness with little built up height) needed to be modeled as well. There have been numerous studies that showed that surface roughness can be Reynolds number sensitive. ${ }^{6,7}$

In order to address these concerns, a scaling test with a semi-span wing of the aircraft to be modeled was conducted. Simulated ice shapes were tested on full-scale and sub-scale wing models in order to understand the issues involved in scaling of this magnitude. The results from these tests were used to determine the simulated ice shapes to be used for the sub-scale complete-aircraft static and dynamic (rotary and oscillatory) tests and to understand how to apply the data to a full-scale aircraft model.

\section{Experimental Methodology}

Three wing models were used in this investigation: full-scale, 5/12-scale, and 1/12-scale. The models represented approximately $2 / 3$ outer semi-span of the aircraft to be modeled. The full scale model was used to simulate the actual aircraft. The 1/12-scale model was used to simulate the subscale complete-aircraft model that was tested in the rotary-balance wind tunnel. The 5/12-scale model was used to bridge the large geometric and Reynolds number gap between the full and 1/12-scale models.

The full scale and 5/12 scale models were tested in the Langley Full Scale Tunnel (LFST) in Hampton, VA. It is a quasi-closed return tunnel with open-walled $30 \times 60 \mathrm{ft}$ test section. It was capable of dynamics pressures of up to 15 psf. The 1/12 scale model was tested in the University of Illinois Subsonic Wind Tunnel. It was an open return tunnel with a 3x4 ft test section and was capable of dynamic pressure of $50 \mathrm{psf}$.

All three models were constructed with a moveable aileron. The full-scale model was of all-aluminum construction representative of an actual aircraft. It was instrumented with pressure belts at three spanwise locations (with 30 ports each). The 5/12-scale model was of fiberglass and plywood construction. The 1/12-scale model consisted of foam surrounding aluminum spars with a fiberglass skin. The 5/12-scale and 1/12-scale models were instrumented with surface pressure taps. The 5/12-scale model had pressure taps at three spanwise locations at the same locations (when nondimensionalized) as the full-scale model. The 1/12-scale model had taps at only 1 spanwise location (with 19 taps) due to space constraints. All three models were instrumented with tufts. The model lift and pitching moment were measured using floor-mounted force balances. The surface pressure and tuft measurements were used for flow diagnostics (particularly separation and stall mechanism). Wall correction was not applied to the data because LFST had an open test section and the test section of the Illinois tunnel was sufficiently larger than the model.

Figure 1(a) shows the full-scale and 5/12-scale models in the test section of LFST. It is important to note that the two models were not tested simultaneously. The 5/12-scale model is in test position and the full-scale model is placed next to it just for demonstration purposes. Figure 1(b) shows the 1/12-scale model in the test section of the Illinois wind tunnel.

As stated previously, the objective of this test was to study both the geometric and Reynolds number scaling issues associated with testing a 1/12-scale complete aircraft model at a greatly reduced Reynolds number. The 5/12scale model was chosen to bridge the large gap between the full scale and 1/12-scale models. Table 1 shows the Reynolds numbers tested with each model. The cases were chosen to eliminate the gap in Reynolds number between the full scale and 5/12-scale models (and between the 5/12-scale and 1/12-scale models). 


\begin{tabular}{cccc}
\multicolumn{4}{c}{ TABLE $1 .-$ REYNOLDS NUMBER TESTED WITH THE THREE MODELS } \\
\hline Scale & $\mathbf{q}$ (psf) & Re (Million) & Comments \\
\hline Full & 15 & 4.2 & Max Re for full scale model in LFST \\
Full & 2.6 & 1.7 & Match max 5/12-scale model Re \\
$5 / 12$ & 15 & 1.7 & Max Re for 5/12-scale model in LFST \\
$5 / 12$ & 7 & 1.2 & Intermediate 5/12 scale case \\
$5 / 12$ & 2 & 0.62 & Match max 1/12-scale model Re \\
$1 / 12$ & 50 & 0.62 & Max Re for 1/12-scale model \\
$1 / 12$ & 18 & 0.38 & Intermediate $1 / 12$ scale case \\
$1 / 12$ & 3 & 0.15 & Match max Re for spin tunnel model \\
\hline
\end{tabular}

Table 2 shows the accuracy of the lift and pitching moment coefficients. Only the force balance uncertainties were considered in these values. This was done in order to gauge the appropriateness of using a single force balance for wide range of freestream dynamic pressures. It shows that the balance provided very good accuracy for all cases except for the lowest dynamic pressures of the 5/12-scale and 1/12-scale models. However, even at these low dynamic pressures, there was enough resolution in the force balance to obtain useful results.

\begin{tabular}{cccccc}
\multicolumn{6}{c}{ TABLE 2.-FORCE BALANCE ACCURACY FOR CASES TESTED. } \\
\hline Model & $\mathbf{R e}\left(\mathbf{x 1 0}^{\mathbf{6}}\right)$ & $\Delta \mathbf{L}(\mathbf{l b})$ & $\boldsymbol{\Delta} \mathbf{M}(\mathbf{f t}-\mathbf{l b})$ & $\Delta \mathbf{C}_{\mathbf{L}}$ & $\Delta \mathbf{C}_{\mathbf{m}}$ \\
\hline Full Scale & 4.2 & 3.99 & 3.125 & 0.0027 & 0.0004 \\
Full Scale & 1.7 & 3.99 & 3.125 & 0.0155 & 0.0022 \\
5/12 Scale & 1.7 & 1.05 & 1.35 & 0.0041 & 0.0022 \\
5/12 Scale & 1.2 & 1.05 & 1.35 & 0.0087 & 0.0048 \\
5/12 Scale & 0.62 & 1.05 & 1.35 & 0.0306 & 0.0168 \\
1/12 Scale & 0.62 & 0.072 & 0.012 & 0.0021 & 0.0007 \\
1/12 Scale & 0.38 & 0.072 & 0.012 & 0.0058 & 0.0021 \\
1/12 Scale & 0.15 & 0.072 & 0.012 & 0.0350 & 0.0124 \\
\hline
\end{tabular}

Three ice shapes were chosen for this study: a 22.5-minute ice-protection failure case, 2-minute initial (preactivation) ice accretion (resembling roughness), and a runback ice shape resulting from the leading-edge thermal anti-ice system. The failure and roughness shapes were obtained using LEWICE 2.0 using the conditions shown in Table 3. The runback shape was typical of those found on this class of airplane during natural and tanker icing encounters.

TABLE 3.-ICING CONDITIONS FOR THE LEWICE ICE SHAPES.

\begin{tabular}{cccccc}
\hline Ice Shape & Aircraft $\boldsymbol{\alpha}$ & $\boldsymbol{V}$ (KCAS) & $\boldsymbol{L} W \boldsymbol{C}\left(\mathbf{g} / \mathbf{m}^{3}\right)$ & $\boldsymbol{M V D}(\boldsymbol{\mu m})$ & $\boldsymbol{O A T}(\mathbf{F})$ \\
\hline 22.5-min. failure & $3.08 \mathrm{deg}$ & 160 & 0.6 & 15 & 14 \\
2 min. roughness & $3.08 \mathrm{deg}$ & 160 & 0.3 & 15 & -4 \\
\hline
\end{tabular}

The full-scale failure shape was constructed using a laser-sintering process. The full-scale 2-minute roughness was simulated using 40-grit sandpaper since it did not have any significant thickness. The full-scale runback shapes were constructed of insulation foam that was cut with a hotwire. The failure and runback shapes had 40-grit (nominal) roughness applied on them to simulate the ice roughness. The ice shapes were constructed in 1 to 2 feet spanwise sections because it could not be built as a single piece. Figure 2 shows the full-scale ice shapes. The ice shapes were attached to the model using double sided tape. The failure shapes were reinforced with speed tape. The gaps between the spanwise sections were filled with putty.

The 5/12-scale failure and upper surface runback shapes were constructed of laser-sintering process. The 5/12scale lower-surface runback shape was constructed of foam that was cut with hotwire. These shapes had 80-grit roughness applied to them. The 5/12-scale 2-minute shape was simulated with both 80 and 120 -grit sandpaper. The upper surface runback shape was also simulated using equivalent balsa strips of various heights at the maximum height location of the runback shape (as shown in Fig. 3).

The 1/12-scale failure shape was also constructed using the laser-sintering process, with 220-grit roughness applied to it. The 2-minute roughness accretion was simulated using various roughness grit applied to double-sided tape. The upper surface runback shape was simulated using simple geometric shapes (such as balsa square and 
piano wire) of various size at different locations. The lower surface runback shape was simulated with a 3/16 in. balsa strip at the same location as the full and 5/12-scale models. An example of an equivalent 1/12-scale runback shape is shown in Figure 4.

\section{Results and Discussion}

The results from the scaling experiments are discussed in this section. The absolute values of $C_{L}, C_{m}$, and angle of attack are not shown because the data were considered proprietary. However, the relative scales are shown in each plot, and all the figures in this paper are plotted to the same scale.

\section{A. Clean Model}

Figure 5(a) shows the clean-model lift curves of the full-scale and 5/12-scale models at various Reynolds numbers. The data shows significant reduction in maximum lift with decreasing Reynolds number. At $R e=1.7$ million, the full-scale model had a $C_{\text {Lmax }} 0.05$ higher than the 5/12-scale model. The stall also occurred at a higher angle of attack. Ideally, both models should have had identical lift curves at matched Reynolds numbers. The observed differences may have been due to some physical differences between the full-scale and 5/12-scale models, such as surface quality (especially near the leading edge), aileron geometry, etc. Another anomaly of note was the 5/12-scale model at $R e=0.62$ million. In the linear region, its lift was measurably lower than at $R e=1.7$ and 1.2 million. This was a shift in $C_{L}$ of approximately 0.03 , which can be explained by the force balance limitations at this Reynolds number (as shown in Table 2).

Figure 5(b) shows the clean-model lift curves of the 5/12-scale and 1/12-scale models. All of the cases show good agreement in the linear range, except the 5/12-scale case at $R e=0.62 \mathrm{million}$, which showed lower lift coefficients, even in the linear region. Again, this may have been due to the resolution of the force balance at this speed, and not actually something that was present in the flowfield.

Figure 6 shows the clean pitching moment coefficients for the three models tested. The figures generally showed earlier breaks in the pitching moment coefficient due to stall as the Reynolds number is decreased. This was consistent with what was observed with the lift curve. The pitching moment of the 5/12-scale, $R e=0.62$ million case did not differ significantly from the $R e=1.7$ and 1.2 million cases in the pre-stall region. As shown in Figure 5(a), this was not the case with the lift curve, further evidence that the offset was a measurement error and not a feature present in the flowfield. An interesting observation is the "dip" in the pitching moment well before stall that appears at $\operatorname{Re}=0.38$ million on the $1 / 12$-scale model. This became more pronounced at $R e=0.15$ million. The cause of the dip was not clear, but one explanation is a trailing edge separation due to low Reynolds number.

\section{B. Failed Ice Protection System Shape}

Figure 7 shows the lift curves for the failed ice-protection system shape. The results show nearly identical lift curves between Reynolds number of 4.2 million and 0.38 million (a factor of 10 decrease in Re). The stall for the 5/12-scale model was slightly more gradual than the full-scale and 1/12-scale models. However, the maximum lift coefficient values in this range were nearly identical. There was a slight change in the lift curve at $R e=0.15$ million, with a reduction in $\mathrm{C}_{\mathrm{l} \text {,max }}$ of 0.02 . The lift curve slope in the linear range was reduced slightly as well. It was not known if this change was real (due to limitations of scaling geometry and $R e$ to this level) or due to measurement uncertainties.

Figure 8 shows the pitching moment coefficients for the failure shape. It shows that the break in the pitching moment coefficient for the full-scale and the 1/12-scale models occurred at the same angle of attack and did not vary with Reynolds number. The 5/12-scale model stalled 1 deg earlier than the other models, but also did not vary with Reynolds number. The insensitivity of the pitching moment coefficient with the Reynolds number was consistent with the lift curves shown in Figure 7.

\section{Ice Protection System Pre-Activation Roughness}

Slightly more variations were observed when the pre-activation roughness simulations were tested. Figure 9 shows the lift curves for the pre-activation roughness. Figure 9(a) shows that on the full-scale model, when the Reynolds number was decreased from 4.2 million to 1.7 million, the $C_{L, \max }$ decreased by 0.02 . The stall angle of attack, however, was not affected. The decrease in $C_{L, \max }$ was much smaller than it was for the clean model, which showed a 0.10 decrease. On the 5/12-scale model, both 80 -grit and 120-grit roughness were tested. Of these two, the 80-grit sandpaper provided a better comparison to the full-scale model. Figure 9(a) shows the lift curves of the 5/12-scale model with 80-grit sandpaper. There was very little change in the lift curve as the Reynolds number was decreased from 1.7 million to 0.62 million. The maximum lift coefficient value was also very close to that observed 
for the full scale model at $R e=1.7$ million. On the 1/12 scale model, roughness heights ranging from bare doublesided tape to 40-grit were studied. Figure 9(c) shows that the 220-grit provided a good simulation. Again, the lift curves did not vary significantly with Reynolds number, with the maximum lift coefficient values remaining nearly constant. The relatively constant maximum lift coefficient values were consistent with both the full-scale and 5/12scale models. These results showed that an aircraft wing with roughness (of the size tested in this study) is relatively insensitive to Reynolds number effects.

Figure 10 shows the pitching moment coefficient values with the pre-activation roughness. The results generally confirm the results shown in the lift curves. The break in the pitching moment did not vary with Reynolds number, indicating that changes in the Reynolds number did not significantly alter the angle of attack at which the model stalled.

The Reynolds number insensitivity is clearly shown in the summary of the $C_{L, \max }$ with varying model size, roughness heights, and Reynolds number (Fig. 11). By using 40-grit sandpaper for the full-scale model, 80-grit sandpaper for the 5/12-scale model, and 220-grit aluminum carbide on the 1/12-scale model, a relatively constant $C_{L, \max }$ was maintained as the Reynolds number was varied from 0.15 million to 4.1 million. On the clean model, the $C_{L, \max }$ varied by 0.20 over this range.

The results from the full-scale and 5/12-scale model suggests that geometrically scaling the grit height is the appropriate method for model-size scaling since 40-grit is approximately twice the height of the 80-grit. However, 220-grit should have been too large for the 1/12-scale model with this method. It is possible that geometric scaling of the roughness grit is only valid when the grits are much taller than the local boundary layer thickness (which may not have been the case for the 1/12-scale model). Also, the roughness grits used on the 1/12-scale model had much lower density than the sandpaper used on the full-scale and 5/12-scale models.

Figure 11 shows that increasing the roughness height resulted in decreased $C_{L, \text { max }}$, and this effect was much larger than that of the Reynolds number effects. On the 1/12-scale model, quadrupling the grit size from 220-grit to 40-grit resulted in a $C_{L, \max }$ decrease of 0.10 . However, quadrupling the Reynolds number from 0.15 million to 0.62 million (with 220-grit roughness grit) resulted in a change of $C_{L, \max }$ of less than 0.03 .

\section{Runback Ice Shape}

Figure 12 shows the lift curves with the runback shapes attached to the models. The results showed that simple geometric scaling of the runback shape did not work. Figure 12(a) shows the lift curves for the full-scale model. It shows that as the Reynolds number was decreased from 4.2 million to 1.7 million, the $C_{L, \max }$ decreased by 0.02 and the stall angle of attack decreased by 2 degrees. Again, this was smaller than that of the clean case. Figure 12(a) also shows the 5/12-scale model with the geometrically scaled runback shape. It also shows a slight change in the lift curve with change in the Reynolds number. However, the maximum lift coefficient values from the 5/12-scale runback case were substantially lower than that of the full-scale case (by approximately 0.06 at matched $R e=1.7$ million). In order to increase the maximum lift coefficient values, smaller runback shapes were tested on the 5/12-scale model. One way to accomplish this was to use simple geometric equivalent shape instead of the geometrically scaled runback shape on the upper surface. The lower-surface ice shape was not changed because it did not have a significant effect on lift. The two equivalent shapes that were tested were 3/32 and 1/16 in. balsa squares. Figure 12(b) shows the effect of these equivalent runback shapes on the lift curves at $R e=1.7$ million. The 1/16 in. balsa was too small and resulted in a lift curve that was nearly identical to the clean model. The 3/32 in. balsa square resulted in a lift curve that was very similar to that of the full-scale model.

For the 1/12-scale model, only equivalent shapes were used. It was anticipated prior to the test (based on fullscale and 5/12-scale test results) that geometric scaling of the 1/12-scale shape was probably not going to work. Figure 12(d) shows the lift curves from one of these shapes. Because the clean model at $R e=0.15$ million had a lower $C_{L, \text { max }}$ than the iced model at $R e=4.2$ million, the iced lift curve could not be exactly duplicated no matter what equivalent shape was used. Instead, an equivalent ice shape that produced relative reduction of the lift coefficient values at $R e=0.15$ million and had post-stall characteristics similar to that of the full-scale shape was sought. Figure 12(c) shows an equivalent runback shape that had a similar reduction in the $C_{L, \max }$ and stall angle of attack from the clean case (when compared to the full-scale runback shape at $\operatorname{Re}=4.2$ million). The post stall behavior was similar as well.

Figure 13 shows the pitching moment of the runback shapes. As was observed for lift, the 3/32 in. balsa shape provided good comparison to the full-scale shape. On the 1/12-scale model, at $R e=0.15$ million, the pitching moment for the iced case broke 5 degrees sooner than the clean case. This was similar to what was observed for the full-scale case at $R e=4.2$ million, and provided a good comparison to the lift results.

It is not clear why the simple geometric scaling of the runback shape did not work for the full-scale and 5/12scale models. The runback shape that was tested on the full-scale model was relatively Reynolds number insensitive 
(Fig. 12(a)). The runback shape that was tested on the 5/12-scale model was Reynolds number insensitive as well. Because of this, it was expected that the lift curves for the full-scale and 5/12-scale models should have similar lift curves at matched Reynolds number. One possible explanation is that there was a surface geometry irregularity near the leading edge of the 5/12-scale model, leading to early transition and stall. This is supported in the clean-model lift curves (Fig. 5), which shows that at matched Reynolds number, the 5/12-scale model had substantially lower $C_{L, \max }$, when compared to the full-scale and 1/12-scale models. This discrepancy was not present on the failure and roughness cases because the ice simulation covered up the leading edge of the model, masking any surface irregularities. The leading edge was not masked for the runback cases, and this could have led to the lower $C_{L, \max }$ values for the 5/12-scale model. However, further study is required to verify this explanation.

\section{Conclusion}

An effort is currently underway to develop icing effects flight simulation models for a typical business jet aircraft. The completed product will be examined as a potential new tool for systems safety to refine hazard classification for ice protection system failure cases, and it will be implemented into a flight training device for pilot evaluation prior to flight tests with ice shapes. The flight model used in the flight simulator will come from testing a 1/12-scale complete aircraft model in a rotary-balance wind tunnel. Because of the significant reduction in both the geometry and the Reynolds number, the scaling relationship between the full scale aircraft and the subscale model was studied.

Three simulated ice accretions were tested in this study: 22.5-minute ice protection system failure shape, 2-minute pre-activation roughness, and a runback shape. The findings for these shapes are summarized below.

- The 22.5-minute failure shape could be scaled from full scale to 1/12 scale through simple geometric scaling. Nearly identical lift curves were maintained (with the geometrically scaled ice shape) as the full-scale model was reduced to 1/12-scale model and the Reynolds number was reduced from 4.1 million to 0.15 million. Similar results were observed for the pitching moment.

- The 2-minute roughness shape exhibited slightly more Reynolds number sensitivity than the failure shape. However, a similar lift and pitching moment curves could be maintained (as the model chord and Reynolds number is decreased) by choosing an appropriate grit height for each model.

- The runback shape exhibited the most Reynolds number dependence. Geometrically scaled runback shapes produced different lift curves on the full-scale and 5/12-scale models, even at matched Reynolds number. The reason for this was not clear. To obtain a comparable lift curve on the 5/12-scale model, a square balsa equivalent geometry was required. A comparable lift curve could not be obtained with the 1/12-scale model because the clean model had lower $C_{L, \max }$ than the iced full-scale model. Because of this, an equivalent ice shape that resulted in similar relative reduction in $C_{L, \max }$ and stall angle of attack (when compared to the clean model at same Reynolds number) was found.

It was not clear why simple geometric scaling did not work for the runback shape. It is also not clear how to choose the correct grit size to scale the 2-minute roughness. In order to address these concerns, additional tests with these types of ice shape are required.

\section{References}

${ }^{1}$ Gingras, D.R., Dickes, E.G., Ratvasky, T.P., and Barnhart, B.P., "Modeling of In-Flight Icing Effects for Pilot Training," AIAA Modeling and Simulation Technologies Conference and Exhibit, Aug. 5-8, 2002, Monterey, CA, AIAA Paper $2002-4605$.

${ }^{2}$ Ratvasky, T.P., Ranaudo, R.J., Barnhart, B.P., Dickes, E.G., and Gingras, D.R., "Development and Utility of a Piloted Flight Simulator for Icing Effects Training,” AIAA 41st Aerospace Sciences Meeting and Exhibit, Jan. 6-9, 2003, Reno, NV, AIAA Paper 2003-0022.

${ }^{3}$ Papadakis, M., Gile Laflin, B.E., Youssef, G.M., and Ratvasky, T.P., “Aerodynamic Scaling Experiments with Simulated Ice Accretions,” AIAA 39th Aerospace Sciences Meeting and Exhibits, Jan. 8-11, 2001, Reno, NV, AIAA Paper $2001-0833$.

${ }^{4}$ Addy, H.E, Broeren, A.P., Zoeckler, J.G., and Lee, S., “A Wind Tunnel Study of Icing Effects on a Business Jet Airfoil,” AIAA 41st Aerospace Science Meeting and Exhibit, Jan. 6-9, 2003, Reno, NV, AIAA Paper 2003-0727.

${ }^{5}$ Dunn, T.A., Loth, E., and Bragg, M.B., “A Computational Investigation of Simulated Large-Droplet Ice Shapes on Airfoil Aerodynamics,” Journal of Aircraft, Vol. 36, No. 5, Sept.-Oct. 1999, pp. 836-837.

${ }^{6}$ Brumby, R.E., “The Effect of Wing Contamination on Essential Flight Characteristics,” SAE Aircraft De-Icing Conference, Douglas Paper 8127, Denver, September, 1988.

${ }^{7}$ Gregory, N. and O’Reilly, C.L., "Low-Speed Aerodynamic Characteristics of NACA 0012 Aerofoil Section, Including the Effects of Upper-Surface Roughness, Simulating Hoar Frost,” ARC R\&M 3726, Jan. 1970. 


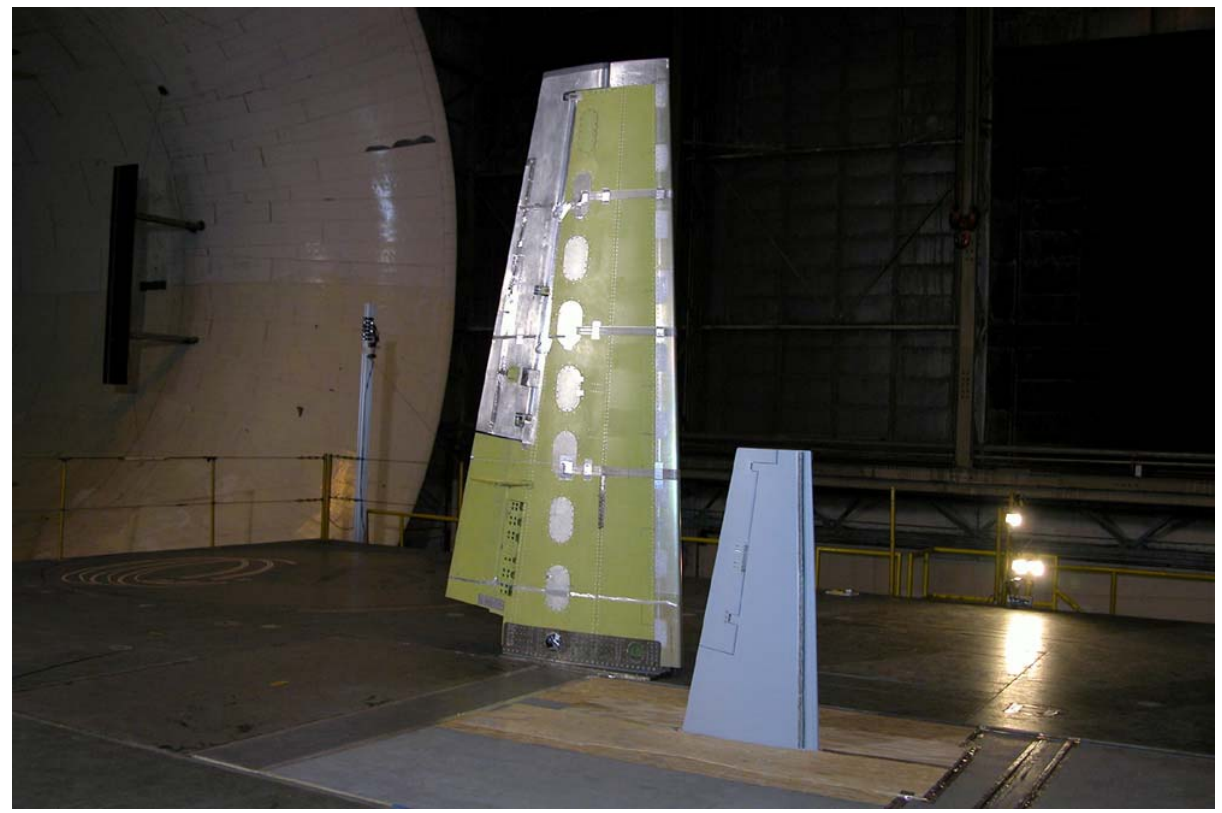

(a) Full-scale and 5/12-scale models in LFST test section.

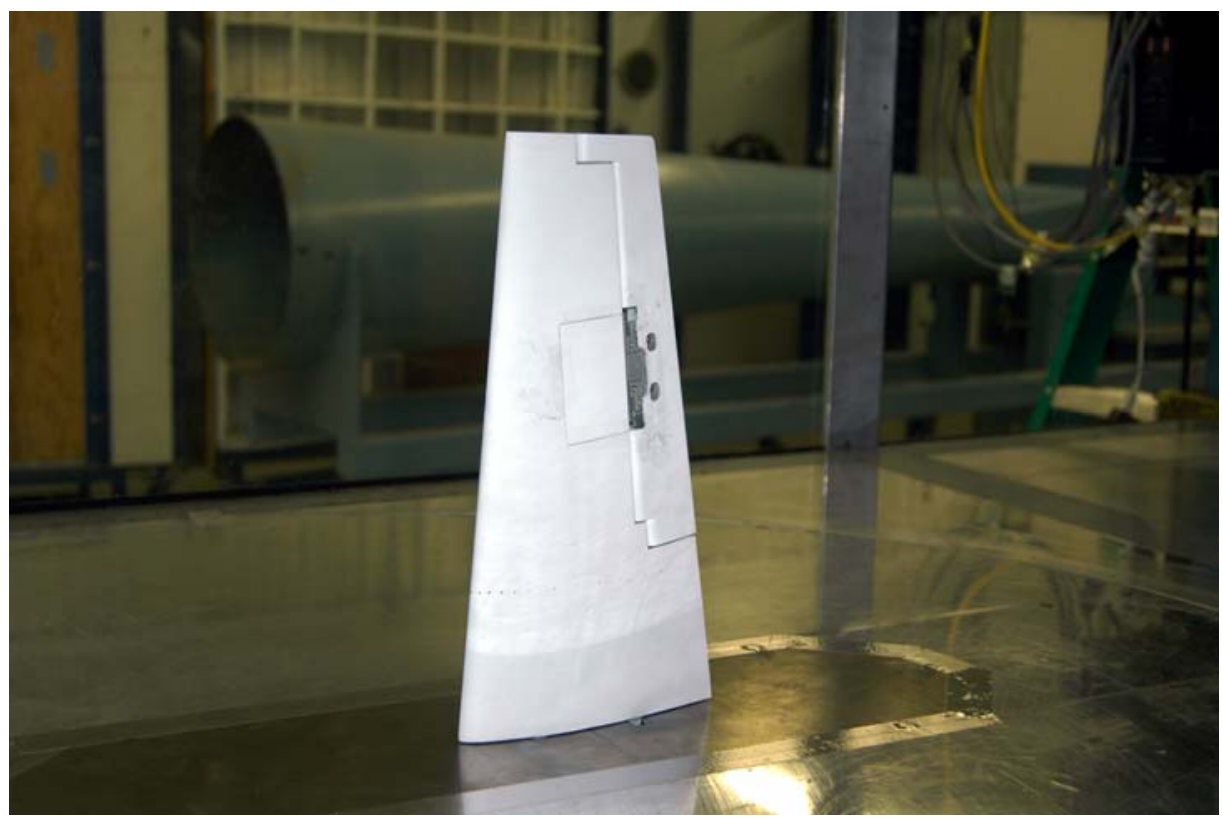

(a) 1/12-scale model in University of Illinois wind tunnel.

Figure 1.-Wind tunnel test sections. 


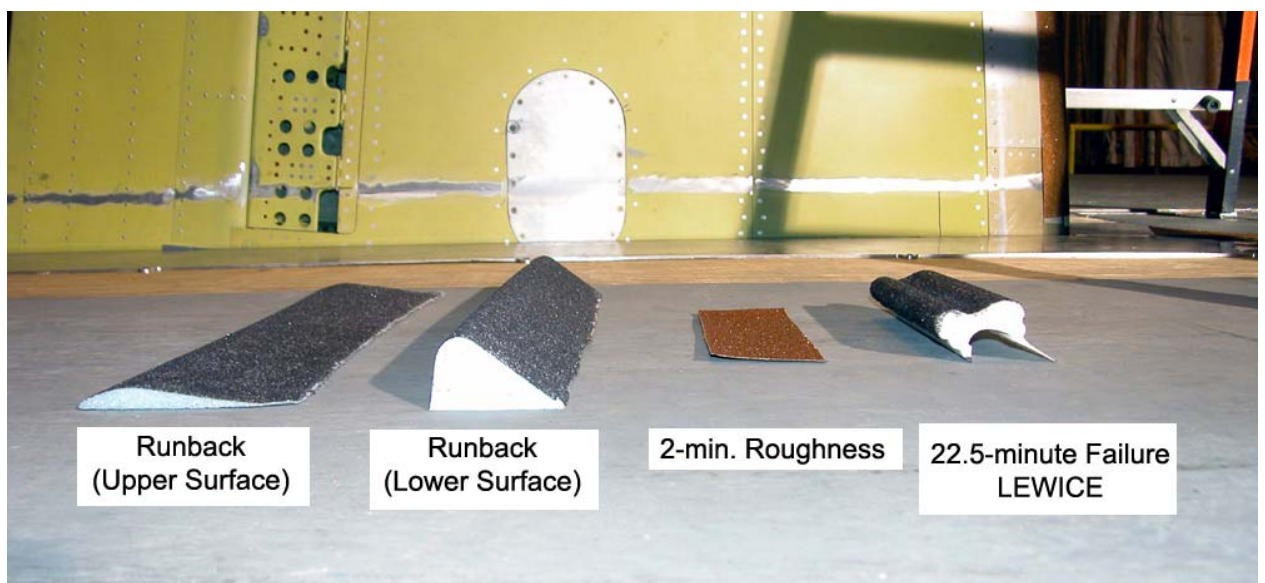

Figure 2.-Full-scale ice shapes.

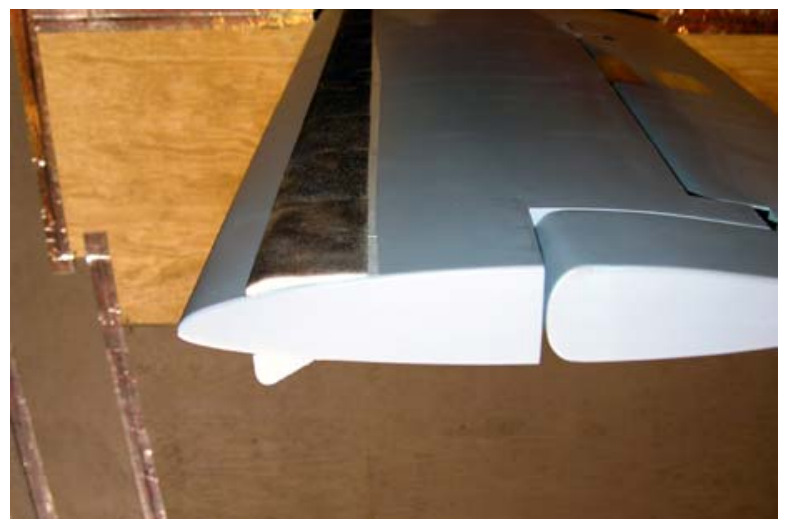

(a) Geometrically-scaled ice shape

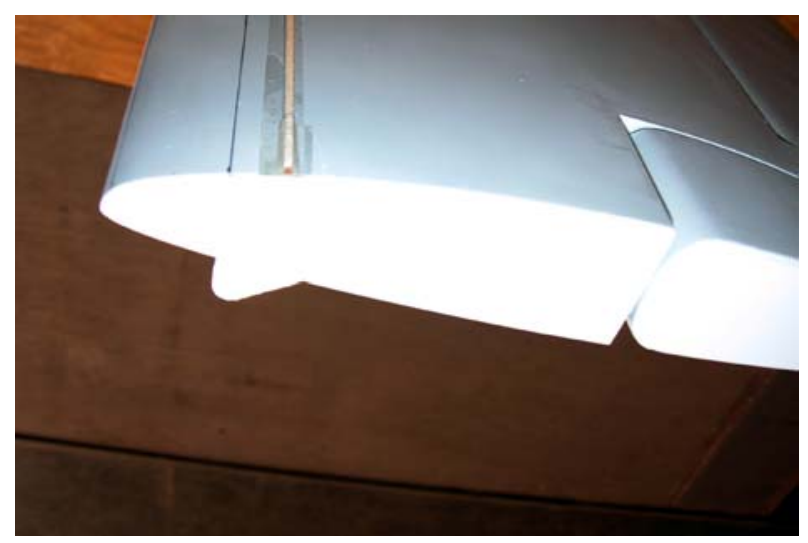

(b) Equivalent balsa ice shape

Figure 3.—5/12-scale runback ice shapes.

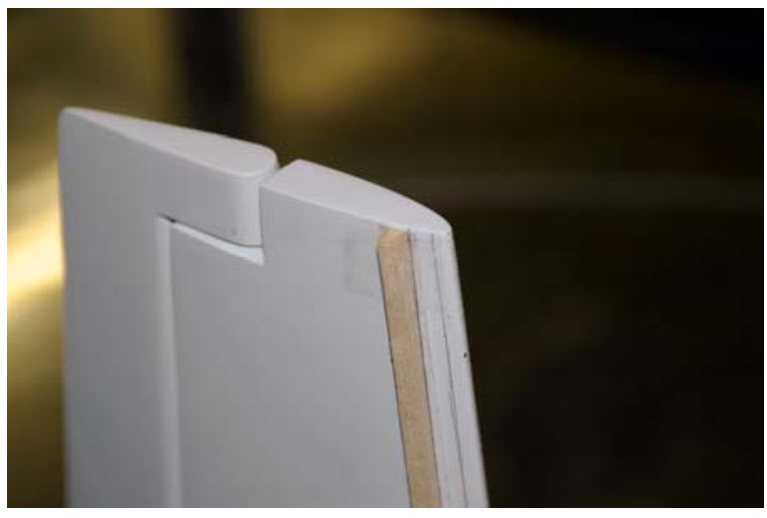

(a) Lower surface

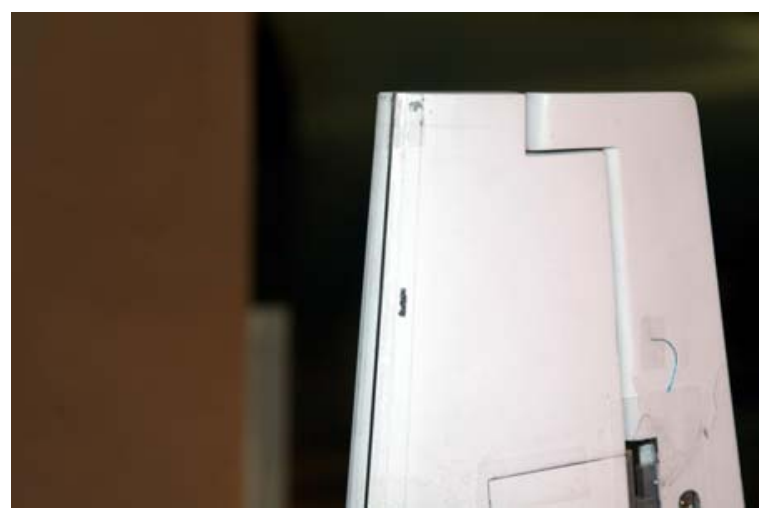

(b) Upper surface

Figure 4.-1/12-scale equivalent runback ice shapes. 


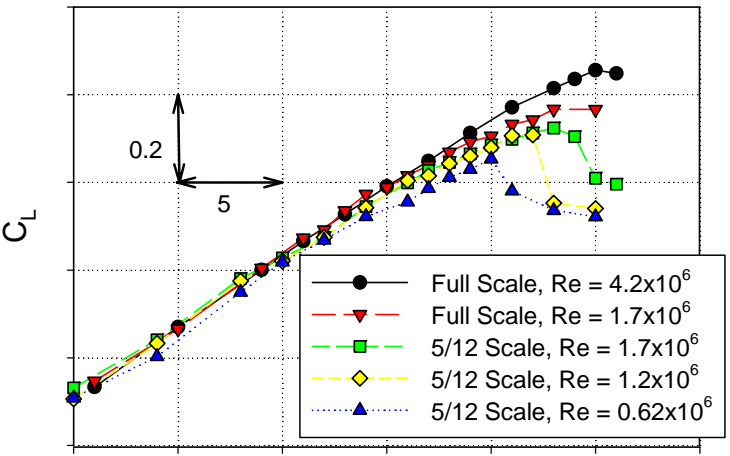

$\alpha$ (deg)

(a) Full and 5/12 scale

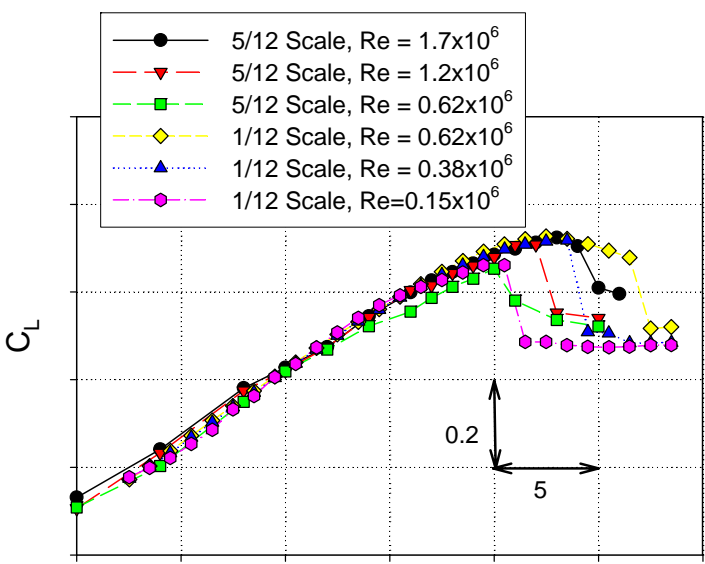

$\alpha$ (deg)

(b) $5 / 12$ and $1 / 12$ scale

Figure 5.-Clean model lift.

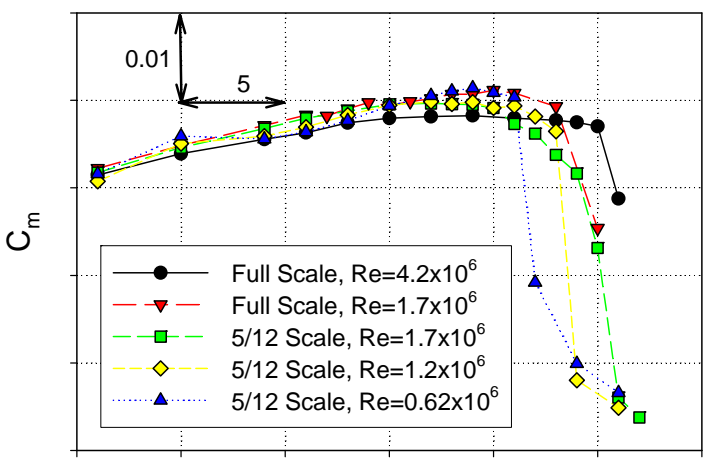

$\alpha$ (deg)

(a) Full and 5/12 scale

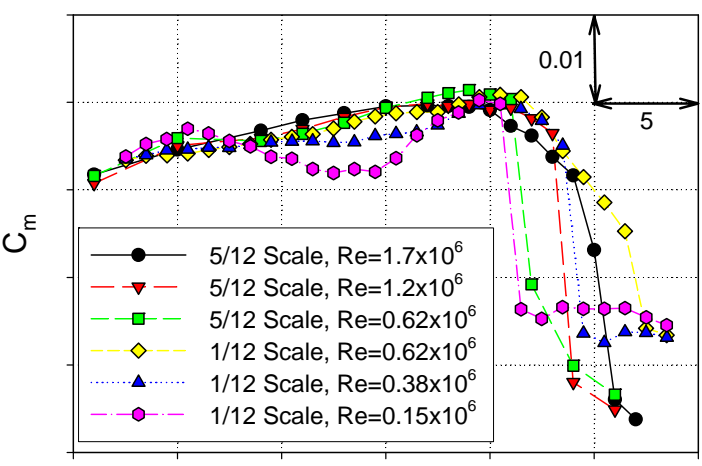

$\alpha$ (deg)

(b) 5/12 and 1/12 scale

Figure 6.-Clean model pitching moment.

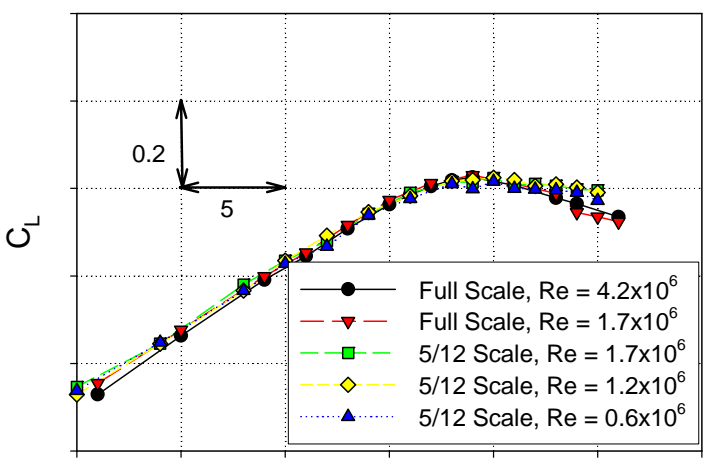

$\alpha(\mathrm{deg})$

(a) Full and 5/12 scale

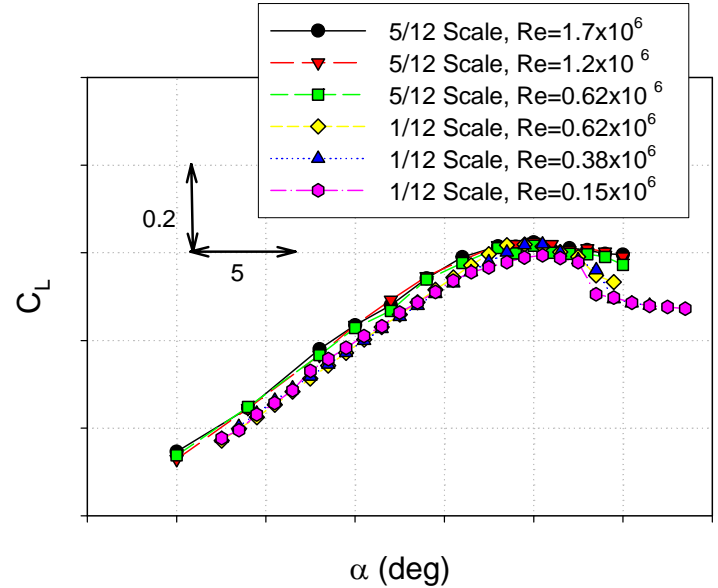

(b) $5 / 12$ and $1 / 12$ scale

Figure 7.—Failure ice shape lift. 


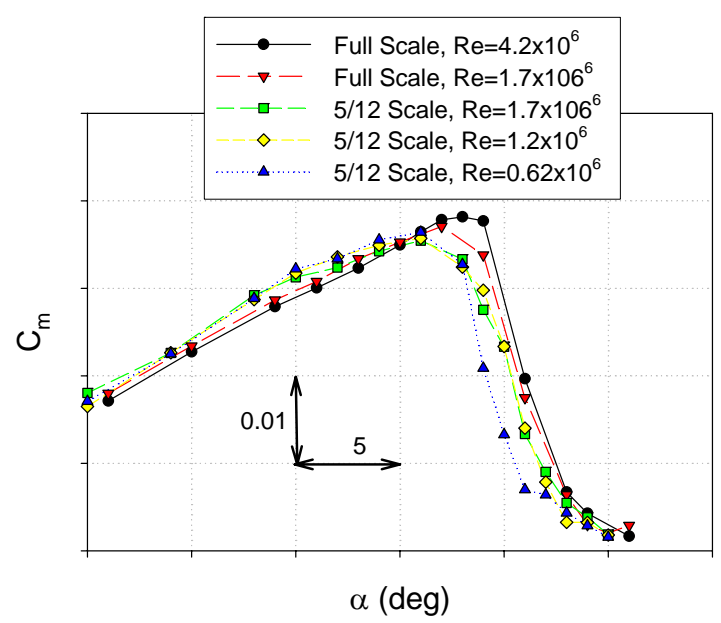

(a) Full and 5/12 scale

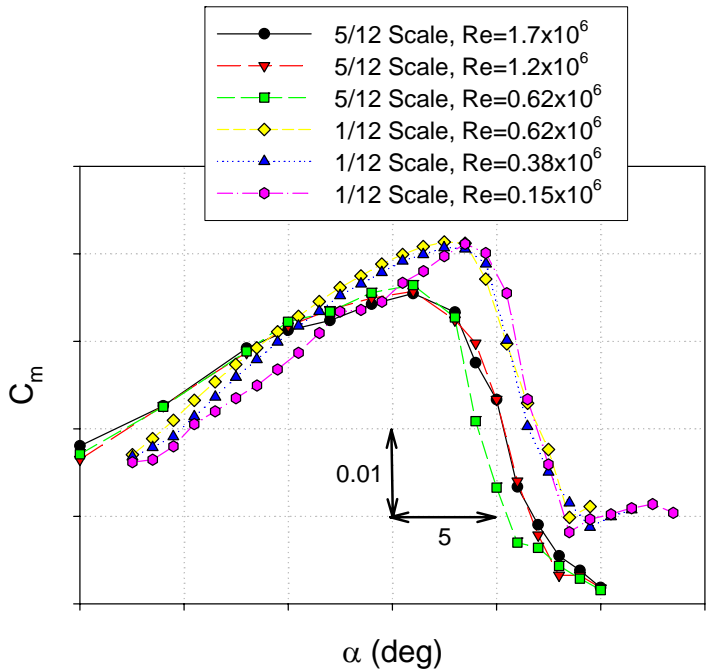

(b) $5 / 12$ and $1 / 12$ scale

Figure 8.-Failure ice shape pitching moment.

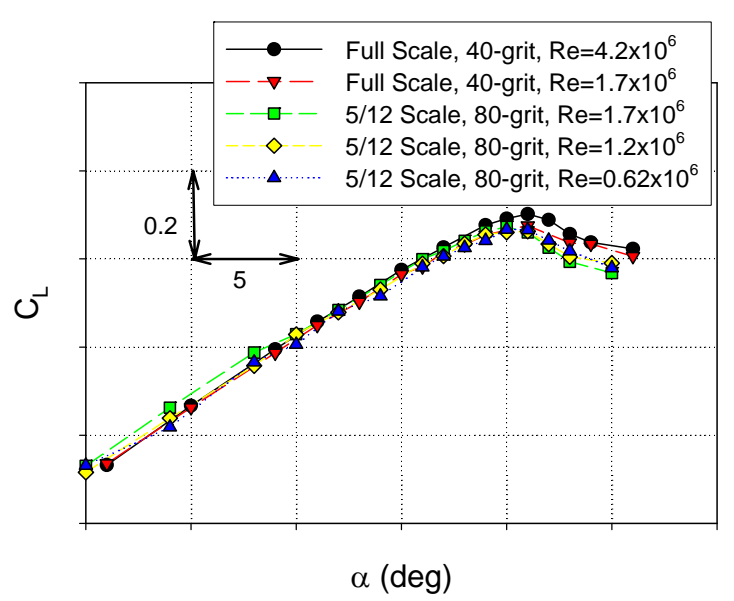

(a) Full and 5/12 scale

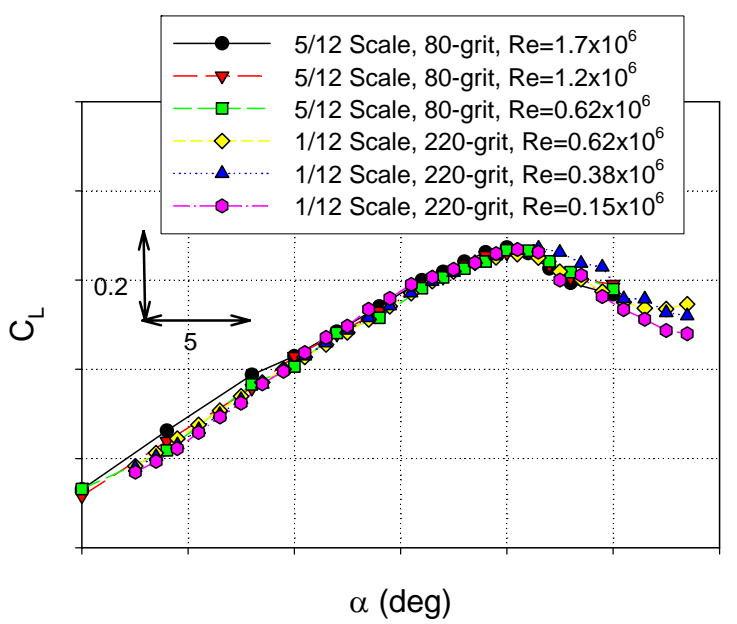

(b) $5 / 12$ and $1 / 12$ scale

Figure 9.-Pre-activation roughness lift. 


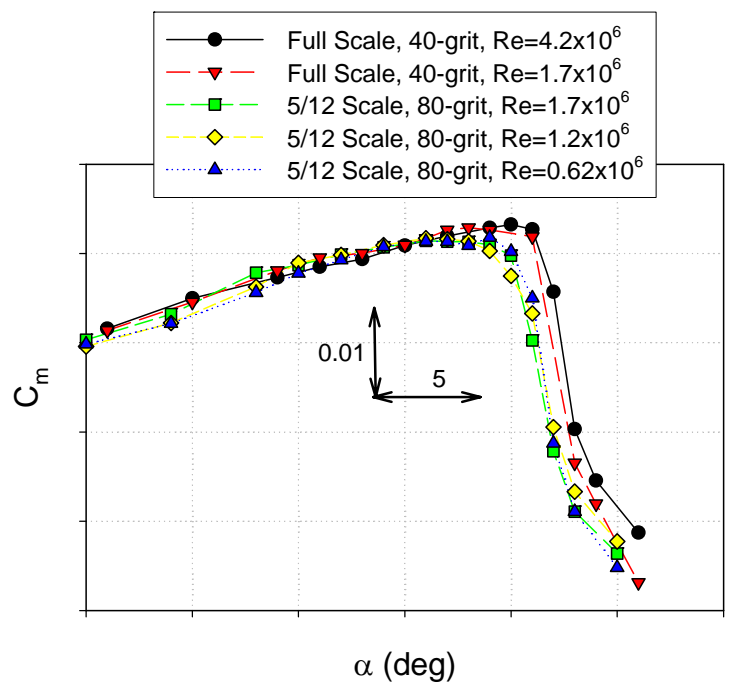

(a) Full and 5/12 scale

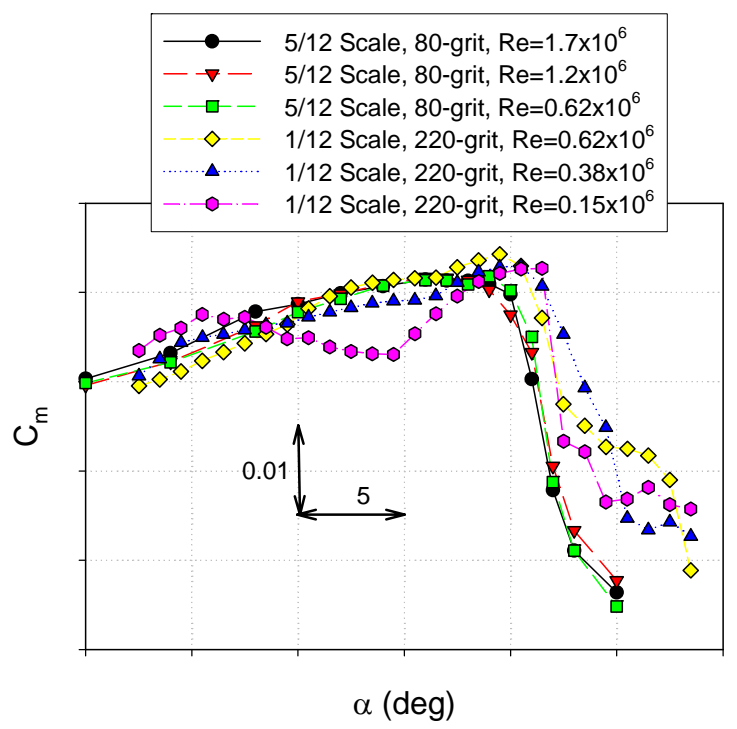

(b) $5 / 12$ and $1 / 12$ scale

Figure 10.-Pre-activation roughness pitching moment.
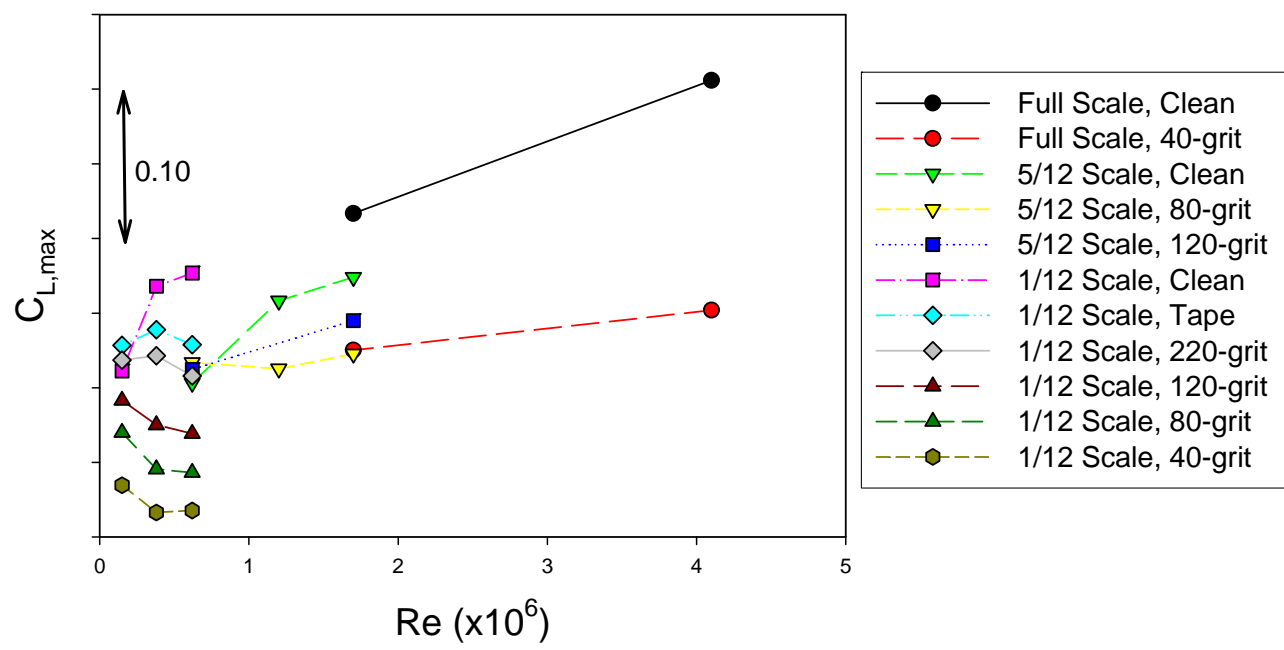

Figure 11.-Summary of $C_{l, \max }$ with various roughness. 


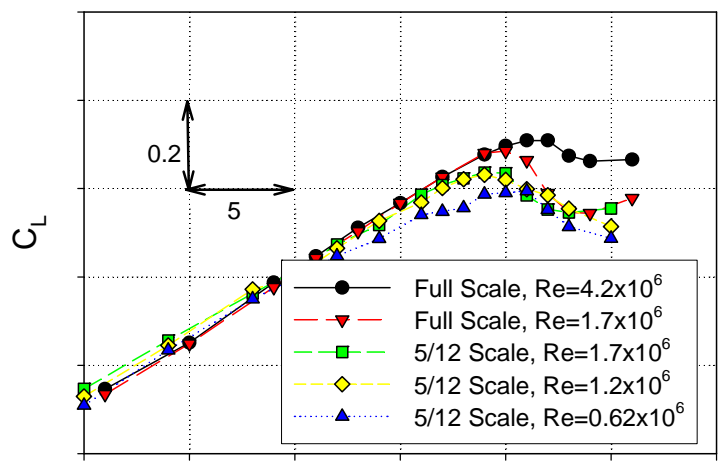

$\alpha$ (deg)

(a) Full and 5/12 scale

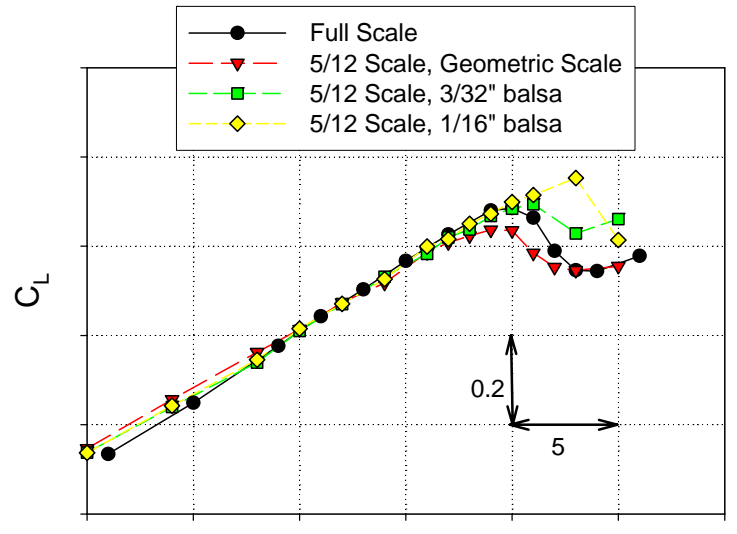

$\alpha(\mathrm{deg})$

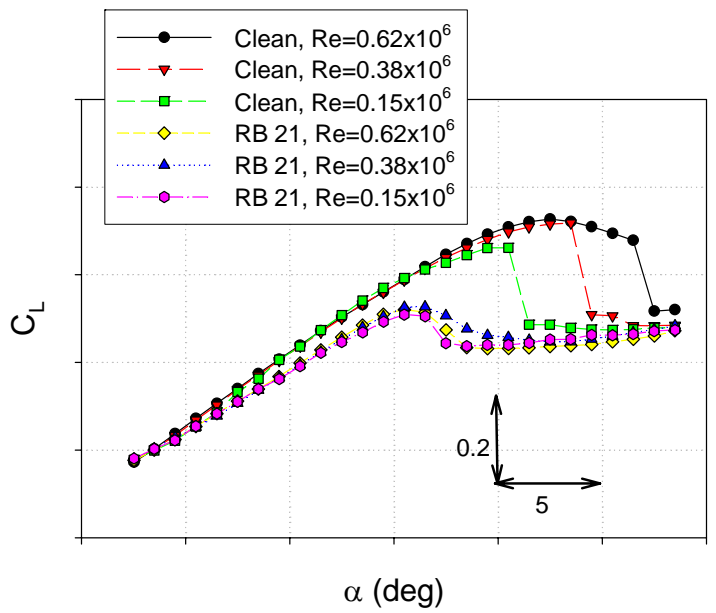

(c) 1/12 scale, equivalent runback shapes

Figure 12.—Runback shape lift. 


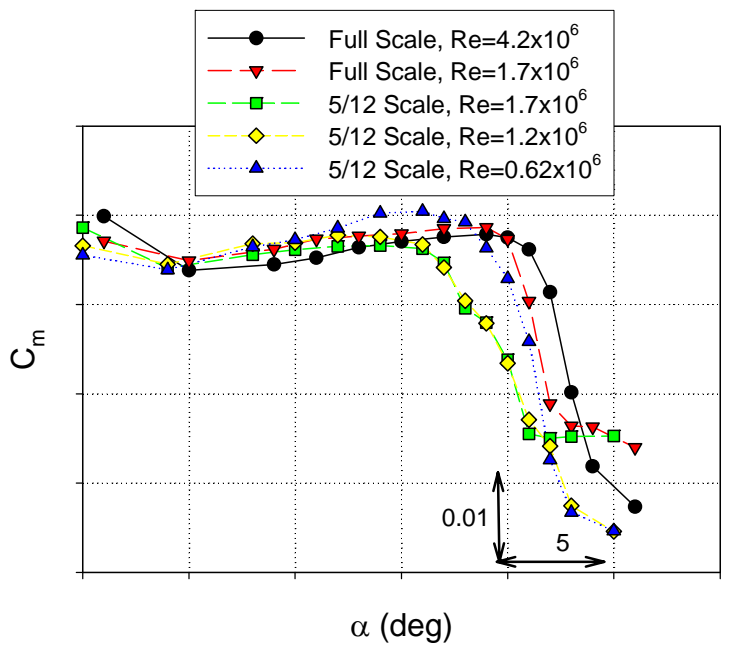

(a) Full and 5/12 scale

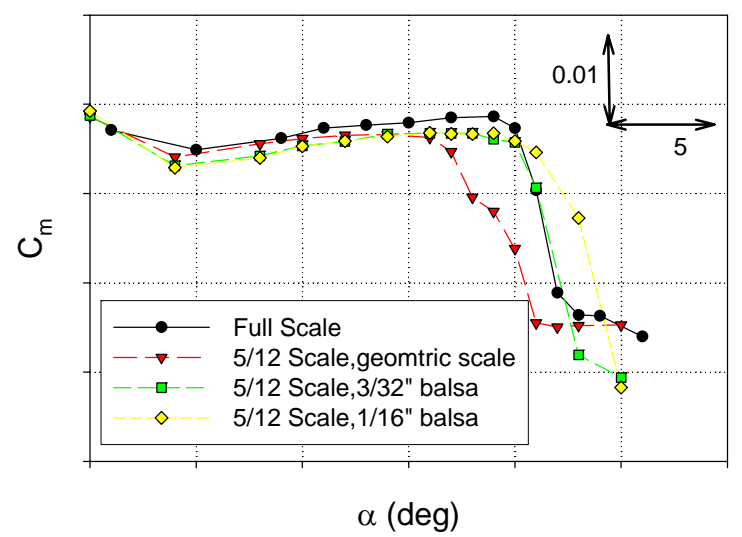

(b) $R e=1.7 \times 10^{6}$

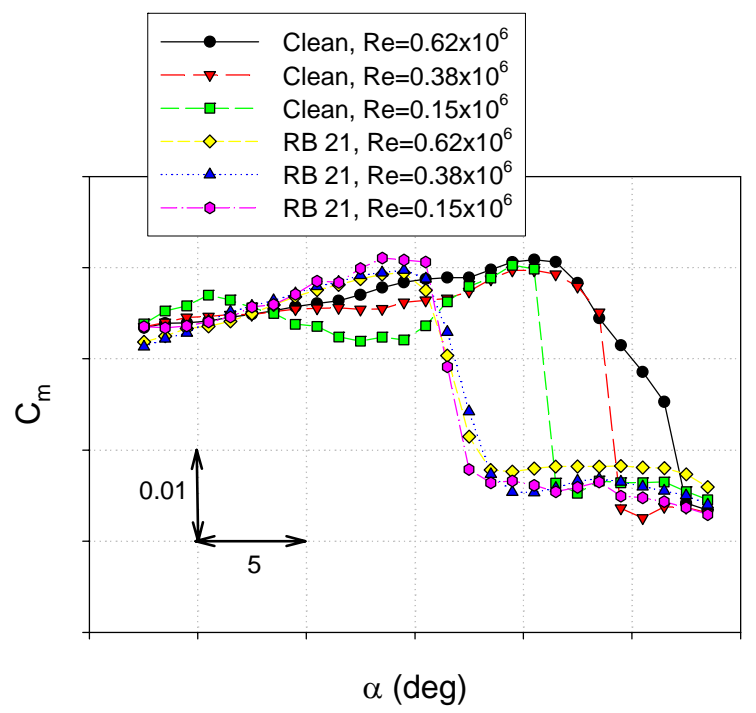

(c) 1/12 scale, equivalent shape 21

Figure 13.-Runback shape pitching moment. 


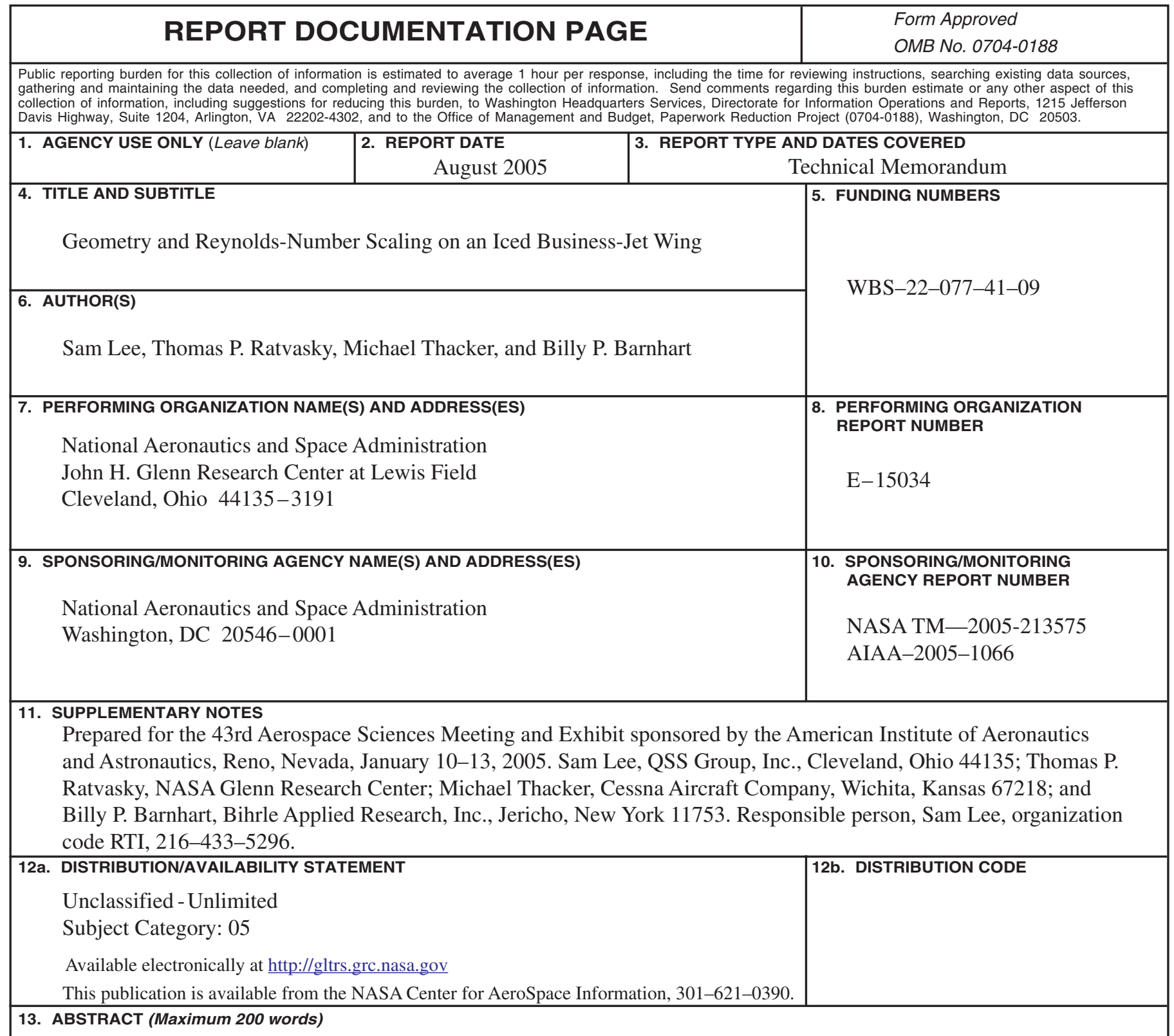

A study was conducted to develop a method to scale the effect of ice accretion on a full-scale business jet wing model to a 1/12-scale model at greatly reduced Reynolds number. Full-scale, 5/12-scale, and 1/12-scale models of identical airfoil section were used in this study. Three types of ice accretion were studied: 22.5 -minute ice protection system failure shape, 2-minute initial ice roughness, and a runback shape that forms downstream of a thermal anti-ice system. The results showed that the 22.5-minute failure shape could be scaled from full-scale to 1/12-scale through simple geometric scaling. The 2-minute roughness shape could be scaled by choosing an appropriate grit size. The runback ice shape exhibited greater Reynolds number effects and could not be scaled by simple geometric scaling of the ice shape.

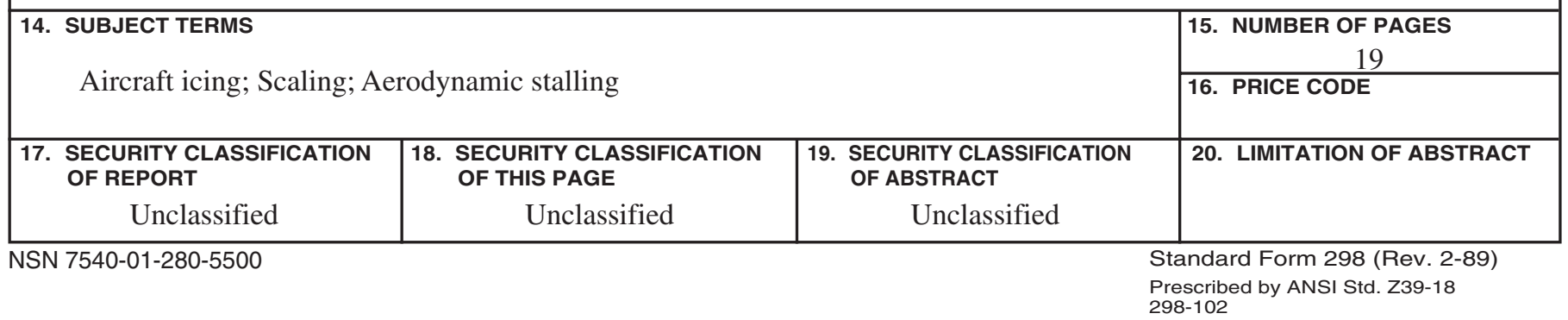



